\title{
Analysing student achievement of advanced pharmacy practice experience learning outcomes
}

\author{
Richard O’Brocta (D), Nicole Paolini Albanese \\ Pharmacy Practice Department, University at Buffalo School of Pharmacy and Pharmaceutical Sciences, United States
}

\section{Keywords}

Accreditation Council for Pharmacy Education (ACPE) Outcome

Pharmacy practice

Professionalism

Skill

Quality improvement

\author{
Correspondence \\ Richard O'Brocta \\ Pharmacy Practice Department \\ University at Buffalo School of Pharmacy and \\ Pharmaceutical Sciences \\ 224 Pharmacy Building \\ Buffalo NY 14214 \\ United States \\ robrocta@buffalo.edu
}

\begin{abstract}
Objectives: To assess the learning outcome achievement of the required Advanced Pharmacy Practice Experiences (APPE) for the purposes of accreditation, quality improvement, and practice readiness. Methods: At the end of each APPE rotation, students were evaluated on 11 professionalism criteria and 25 skills criteria via a rubric. For the four required rotations (ambulatory patient care, community pharmacy, inpatient general medicine patient care and hospital/health system pharmacy), professionalism and skills outcomes data for the class of 2020 were analysed. Results: A total of $6,293 / 6,303(99.84 \%)$ of the professionalism ratings met expectations (received a score $\geq 2$ ). The median professionalism rating was 3 . A total of $14,286 / 14,325$ (99.7\%) of the skills ratings met expectations (received a score $\geq 3$ ). The median skills rating was 4 . Conclusion: Calculating and analysing APPE student achievement of learning outcomes supports accreditation standards, can be used for quality improvement and measures practice readiness.
\end{abstract}

\section{Introduction}

Schools should be monitoring student achievement of learning outcomes to maintain a quality improvement process based on recommendations from pharmacy organisations and accreditation standards (ACPE, 2015a). In 2017, the Fédération Internationale Pharmaceutique/ International Pharmaceutical Federation (FIP) published the Nanjing Statements on Pharmacy and Pharmaceutical Sciences (FIP, 2017). "The Nanjing Statements are intended for education providers, including Schools of Pharmacy and providers of Continuing Professional Development and Continuing Education. They are to be used for the purposes of self-assessment and monitoring (at country level or education provider level), identification of gaps and strategic planning, and improving the process of education" (FIP, 2017, p. 1). Clusters 7.1 and 7.2 discuss the importance of using metrics for quality improvement of the educational program (FIP, 2017). In the United States, the Accreditation Council for Pharmacy Education (ACPE) most recently published "Standards 2016" (ACPE, 2015a). Standard 24.4, which focuses on continuous improvement, provides the following: "The college or school uses the analysis of assessment measures to improve student learning and the level of achievement of the Educational Outcomes" (ACPE, 2015a, p. 17). ACPE's guidance for 2016 Standards document section $10 p$ asks that the syllabi contain the learning outcomes and how the learning outcomes will be assessed for a course (ACPE, 2015b).

Pharmacy students are required to complete hands-on Advanced Pharmacy Practice Experiences (APPEs) as a culmination of their didactic and introductory pharmacy practice experiences education (ACPE, 2015a). Competency-based standards have long been discussed to enhance pharmacy education, but current accreditation standards do not incorporate it (Law, Bates, Williams et al., 2019; Katoue \& Schwinghammer, 2020). ACPE standard 13.6 requires students to complete one APPE rotation in four different practice 
settings: 1) community pharmacy (Community); 2) ambulatory patient care (Ambulatory Care); 3) hospital/health system pharmacy (Health System); and 4) inpatient general medicine patient care (Medicine). Each required rotation must be of a minimum of 160 hours (ACPE, 2015a). The four required rotations are defined as follows:

\section{Community Pharmacy (Community):}

A community rotation provides the student with direct drug distribution and counselling activities. There may also be clinical activities going on concurrently; however, the main objective of this type of rotation is to dispense medications in a safe and timely manner following all legal and regulatory requirements of the site/state. Practice management will also be emphasised.

\section{Ambulatory Patient Care (Ambulatory Care):}

An outpatient clinical rotation provides the student with direct patient care activities. The student is also expected to participate actively as part of an interprofessional team. Depending on the actual site, there may also be dispensing activities going on concurrently; however, the main objective of this type of rotation is to provide medication therapy management and education for patients' chronic diseases.

\section{Hospital/Health-System Pharmacy (Health System):}

The purpose of this rotation is for the student to understand how the right medication gets to the right patient at the right time. It usually includes exposure to the drug distribution system, Intravenous (iv) admixture preparation, controlled substance management, inventory control, among others. The focus is on system management and continuous quality improvement.

4. Inpatient General Medicine Patient Care (Medicine):

A general medicine rotation provides the student with direct patient care experience in the inpatient setting, utilising a rounding service. The student will manage a diverse patient population with a variety of common conditions seen in adult care patients. The student will also contribute actively as a member of an interprofessional healthcare team.

The purpose of this paper is to assess the learning outcome achievement of APPE students in the four required settings for the purposes of accreditation, quality improvement, and practice readiness.

\section{Methods}

One hundred and sixteen students in the class of 2020 completed a total of 573 rotations with 257 preceptors in 13 different States. The distribution of preceptors by State is available in Table I, with the majority from New
York State. The number of preceptors for Ambulatory Care, Community, Health-System, and Medicine were $65,82,52$, and 58 , respectively. One hundred fortyseven students completed an Ambulatory Care rotation, 186 completed a Community rotation, 124 completed a Medicine rotation, and 116 completed a Health-System rotation. Preceptors were required to evaluate the student's performance utilising professionalism and skills rubrics on every rotation. To do this, preceptors had access to a secure web-based evaluation tool that transmits the student's evaluation ratings to both the student and school faculty in realtime. The student's final grade was then calculated based on this evaluation.

Table I: Preceptors by State

\begin{tabular}{cc}
\hline State & Number of preceptors \\
\hline AK & 1 \\
AZ & 2 \\
CA & 3 \\
CO & 1 \\
FL & 1 \\
GA & 1 \\
IL & 1 \\
KY & 2 \\
MD & 1 \\
ME & 1 \\
MI & 1 \\
NJ & 4 \\
NY & 4 \\
\hline
\end{tabular}

For this study, preceptor evaluation of student data was collected retrospectively and sorted by each of the four required rotation types for the class of 2020. There were 11 Professionalism criteria rated on a scale of 1-3 (1=does not meet expectations, $2=$ meets expectations, and $3=$ exceeds expectation), with a rating of " 2 " considered minimum competency and a rating of " 1 " considered a low score (Table II). The 25 Skills criteria were rated on a scale of 1-5, with " 1 " being the lowest rating and " 5 " being the highest, with a rating of " 3 " considered minimum competency and a rating of " 1 " or " 2 " considered a low score (Table III). Data were available in the web-based evaluation tool and were exported to Microsoft Excel for convenient sorting, analysis, and descriptive statistics reporting.

\section{Results}

Tables II and III describe the learning outcomes and evaluation criteria for the Professionalism and Skills learning outcomes, respectively. 


\section{Table II: Professionalism criteria}

\begin{tabular}{|c|c|}
\hline Outcome 1 & Motivation: Displays eagerness to learn and to effectively care for patients. \\
\hline Outcome 2 & $\begin{array}{l}\text { Commitment to excellence: Actively engaged; demonstrates strong work ethic; strives to exceed minimum requirements; } \\
\text { punctual; prepared; conscientious; seeks additional knowledge and skills }\end{array}$ \\
\hline Outcome 3 & Adaptability: Able to modify behaviour accordingly when presented with different situations \\
\hline Outcome 4 & $\begin{array}{l}\text { Accountability: Accepts personal responsibility (e.g., for own learning, patient care, etc.); demonstrates preparedness, } \\
\text { punctuality, and reliability with commitments in a timely manner; is accountable for their performance, initiates activities } \\
\text { when necessary, and contributes overall to the profession; exhibits awareness and adherence to various site policies and } \\
\text { procedures }\end{array}$ \\
\hline Outcome 5 & $\begin{array}{l}\text { Time management } \& \text { organisation constructively uses spare time, able to prioritise and manage multiple tasks, } \\
\text { independently manages times and tasks, meets deadlines }\end{array}$ \\
\hline Outcome 6 & $\begin{array}{l}\text { Communication: oral, written and non-verbal communication is courteous, respectful, and situationally appropriate; listens } \\
\text { attentively. }\end{array}$ \\
\hline Outcome 7 & $\begin{array}{l}\text { Integrity \& trustworthiness: Demonstrates high degree of integrity, truthfulness, and fairness; adheres to ethical } \\
\text { standards; maintains confidentiality }\end{array}$ \\
\hline Outcome 8 & Teamwork: Willingness to assist and interacts effectively with others; inspires trust among team members \\
\hline Outcome 9 & $\begin{array}{l}\text { Professional demeanour: Displays a positive attitude; nonjudgmental; controls emotions appropriately; carries oneself with } \\
\text { professional presence }\end{array}$ \\
\hline Outcome 10 & $\begin{array}{l}\text { Compassion \& respect for others: Displays empathy and sensitivity; respectful of different socioeconomic backgrounds and } \\
\text { cultural traditions; avoids promoting gossip and rumour; respects authority }\end{array}$ \\
\hline Outcome 11 & $\begin{array}{l}\text { Independent learner: Commits to lifelong learning; seeks and applies feedback for self-improvement; sets and achieves } \\
\text { realistic goals (S.M.A.R.T.); maintains personal health and well-being; avoids harmful behaviours }\end{array}$ \\
\hline
\end{tabular}

Rating scores: $1=$ Does not meet expectations; 2 = Meets expectations; 3 = Exceeds expectations

\section{Table III: Skills criteria}

\begin{tabular}{|c|c|}
\hline \multicolumn{2}{|c|}{ Communication skills } \\
\hline Outcome 1 & $\begin{array}{l}\text { Verbal Communication with Preceptor and Other Healthcare Professionals: Effective communication (verbal and } \\
\text { non-verbal); uses clear and correct language; sensitive to surroundings }\end{array}$ \\
\hline Outcome 2 & $\begin{array}{l}\text { Written Communication: Critically presented, well-cited info with articulation, clarity and insight (e.g. assignments, } \\
\text { emails) }\end{array}$ \\
\hline Outcome 3 & $\begin{array}{l}\text { Medical Notes: (e.g. MTM, SOAP, pharmacotherapy consult, pharmacokinetic note): Organised; no grammatical } \\
\text { or spelling errors; includes all pertinent info; note follows logical sequence; thorough yet concise; avoids bias }\end{array}$ \\
\hline \multicolumn{2}{|c|}{ Drug information } \\
\hline Outcome 4 & $\begin{array}{l}\text { Literature Retrieval / Appropriate Use of Resources: Effectively uses a variety of sources. Designs effective, } \\
\text { thorough search strategy }\end{array}$ \\
\hline Outcome 5 & $\begin{array}{l}\text { Literature Evaluation \& Formulating a Response: Able to evaluate literature with sophistication and depth; Applies } \\
\text { the obtained information to appropriately answer the specific DI question }\end{array}$ \\
\hline \multicolumn{2}{|c|}{ Pharmacotherapeutic knowledge } \\
\hline Outcome 6 & Pathophysiology of Common Disease States: Able to explain pathophysiologic principles and details \\
\hline Outcome 7 & $\begin{array}{l}\text { Pharmacology and Pharmacokinetic Principles: Able to explain drug mechanisms and pharmacokinetic principles } \\
\text { of common therapies and drug classes }\end{array}$ \\
\hline Outcome 8 & $\begin{array}{l}\text { Essential Therapeutic Principles: Able to construct/critique medication regimen rationales and approaches to } \\
\text { treatment }\end{array}$ \\
\hline Outcome 9 & $\begin{array}{l}\text { Interpretation and Analysis of Laboratory Data: Able to interpret and analyse common clinical laboratory test data } \\
\text { (e.g., can utilise normal ranges, recognise lab error, understand rationale for ordering specific tests, apply results } \\
\text { appropriate, etc.). }\end{array}$ \\
\hline Outcome 10 & $\begin{array}{l}\text { Evaluation of Preventative Care: Able to evaluate patient for consideration of prevention and wellness } \\
\text { recommendations (e.g., immunisations, self-care, wellness, etc.). }\end{array}$ \\
\hline \multicolumn{2}{|c|}{ Medication distribution } \\
\hline Outcome 11 & $\begin{array}{l}\text { Prescription Interpretation: Accurately interprets prescription orders and/or safely dispenses medications while } \\
\text { applying professional standards and legal guidelines }\end{array}$ \\
\hline Outcome 12 & $\begin{array}{l}\text { Inventory Management: Uses and evaluates drug acquisition, inventory control and time sensitive medication } \\
\text { distribution systems and related technology, while documenting and maintaining quality. }\end{array}$ \\
\hline Outcome 13 & $\begin{array}{l}\text { Systems Management: Applies principles of personnel, financial and marketing management to medication } \\
\text { distribution and control systems in pharmacy practice. }\end{array}$ \\
\hline
\end{tabular}


Table III: Skills criteria (Continued)

\begin{tabular}{|c|c|}
\hline \multicolumn{2}{|c|}{ Medication distribution (continued) } \\
\hline Outcome 14 & Hypothesis and Objectives: Identifies relevant hypotheses and objectives of project. \\
\hline Outcome 15 & $\begin{array}{l}\text { Analysis: Utilises available resources to design and carry out [statistical/ pharmacokinetic/ pharmacoeconomic/ } \\
\text { etc.] analysis of research data; provides graphical representation of data; interprets data into meaningful findings. }\end{array}$ \\
\hline Outcome 16 & $\begin{array}{l}\text { Presentation of Findings: Effectively presents the findings of their project to other individuals (PowerPoint, } \\
\text { poster, manuscript, etc.); is able to describe significance and relevance of the project. }\end{array}$ \\
\hline \multicolumn{2}{|c|}{ Pharmacist patient care process } \\
\hline Outcome 17 & $\begin{array}{l}\text { Collect: Assures the collection of the necessary subjective and objective information about the patient in order to } \\
\text { understand the relevant medical/medication history and clinical status of the patient }\end{array}$ \\
\hline Outcome 18 & $\begin{array}{l}\text { Assess: Assesses the information collected and analyses the clinical effects of the patient's therapy in the context of } \\
\text { the patient's overall health goals in order to identify and prioritise problems and achieve optimal care. }\end{array}$ \\
\hline Outcome 19 & $\begin{array}{l}\text { Plan: Develops an individualised patient-centred care plan, usually in collaboration with other health care } \\
\text { professionals and the patient or caregiver, that is evidence-based and cost-effective. }\end{array}$ \\
\hline Outcome 20 & $\begin{array}{l}\text { Implement: Implements the care plan usually in collaboration with other health care professionals and the patient } \\
\text { or caregiver. }\end{array}$ \\
\hline Outcome 21 & $\begin{array}{l}\text { Follow-up (monitor and evaluate): Monitors and evaluates the effectiveness and safety of the care plan and } \\
\text { modifies the plan usually in collaboration with other health care professionals and the patient or caregiver as } \\
\text { needed. }\end{array}$ \\
\hline \multicolumn{2}{|c|}{ Miscellaneous skills } \\
\hline Outcome 22 & $\begin{array}{l}\text { Empathy: Treats patients and families with dignity; respects patient privacy (e.g., HIPAA), values and belief } \\
\text { systems; advocates for patients; places patients' needs above their own. }\end{array}$ \\
\hline Outcome 23 & $\begin{array}{l}\text { Awareness of Patient Safety: Promotes a culture of safety; utilises systems to prevent errors; reviews sites } \\
\text { policies and procedures. }\end{array}$ \\
\hline Outcome 24 & $\begin{array}{l}\text { Critical Thinking and Decision Making: Examines healthcare and/or patient care issues in a rational and logical } \\
\text { manner to evaluate, analyse and synthesise information and knowledge in order to make sound decisions }\end{array}$ \\
\hline Outcome 25 & $\begin{array}{l}\text { Interprofessional Collaborative Practice: Demonstrates the ability to integrate within an interprofessional team so } \\
\text { as to deliver the highest level of pharmacy care. Employs these skills to cooperate, collaborate, and integrate } \\
\text { pharmacy care with interprofessional team members to ensure that patient care is continuous, coordinated, } \\
\text { effective, and reliable. }\end{array}$ \\
\hline
\end{tabular}

\footnotetext{
Rating scores:

1 = Technician/P1-Student requires specific direction, direct supervision and significant correction for performance improvements

2 = Intern/P2/P3-Student requires direct supervision and frequent correction and accepts feedback for performance improvement

$3=$ Experienced intern/P4-Student requires limited correction, is self-directed and seeks guidance as necessary

$4=$ Resident or recent graduate-Student is able to accurately complete as an independent practitioner

5 = Experienced pharmacist-Student has mastered ability as an independent practitioner and is able to give meaningful feedback to other learners
}

Figures 1 and 2 represent the number of Professionalism and Skills rated as a low score outcome per type of APPE rotation, respectively. An empty cell indicates no low scores for that outcome for that APPE rotation. As shown in Figure 1, a total of 10/6,303 $(0.16 \%)$ of the Professionalism learning outcomes were scored as low (score of 1), and 6,293/6,303 (99.84\%) were scored as meeting expectations (score of 2 or better), with a median rating of $3(3,2)$. Figure 2 shows that $44 / 24,325(0.31 \%)$ of the Skills learning outcomes were scored as low (score of 1 or 2), and 14,286/14,325 (99.7\%) were scored as meeting expectations (score of 3 or better), with a median rating of $4(4,3)$. For the
Professionalism criteria, learning outcomes 1, 2, and 5 had the greatest number of low scores occurring most frequently on Medicine rotations (Figure 1). For the Skills criteria, learning outcome 1 had the largest number of low scores, occurring on all four required APPE rotations (Figure 2). The Medicine rotation had the highest number of low scores for professionalism outcomes $(n=8)$ and skills outcomes $(n=20)$, while Ambulatory Care and Community rotations had the fewest $(n=0)$. Overall, four students contributed to the low scores for the professionalism learning outcomes, and twelve students contributed to the low scores for skills learning outcomes. 


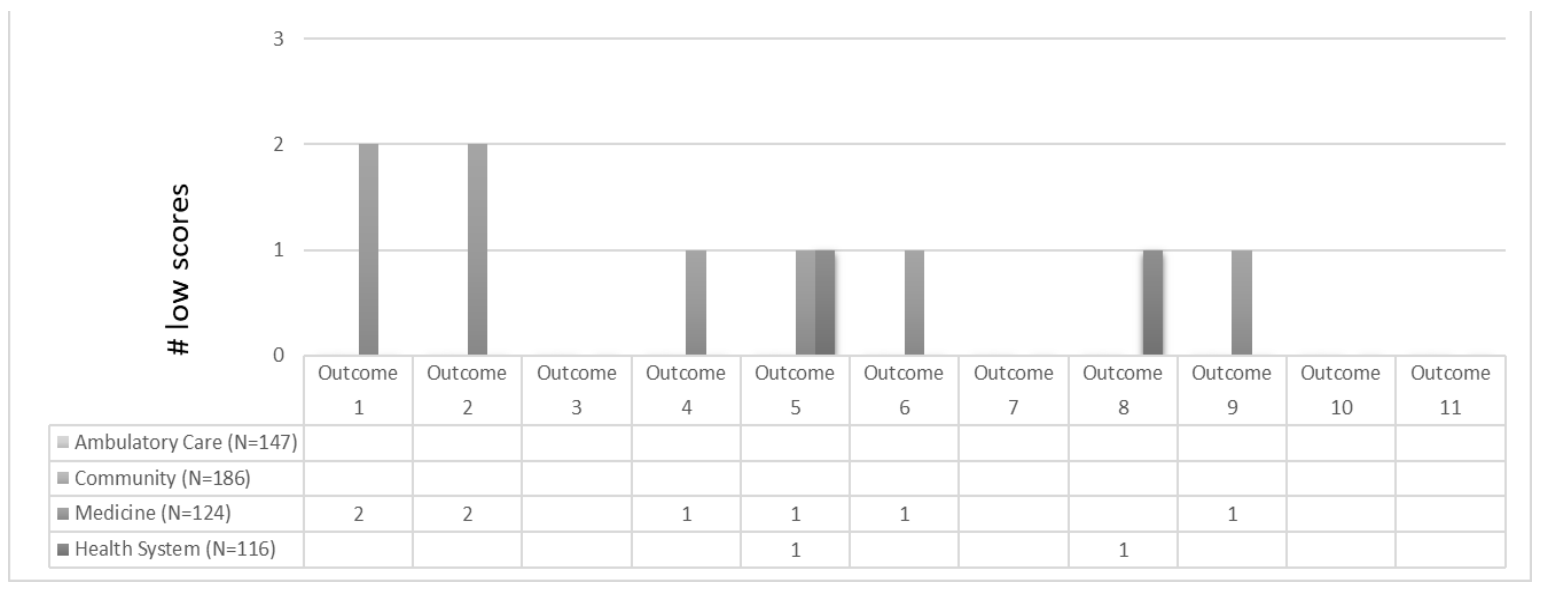

Figure 1: 2019-2020 APPE core rotation professionalism outcome low scores (less than 2: range 1-3)

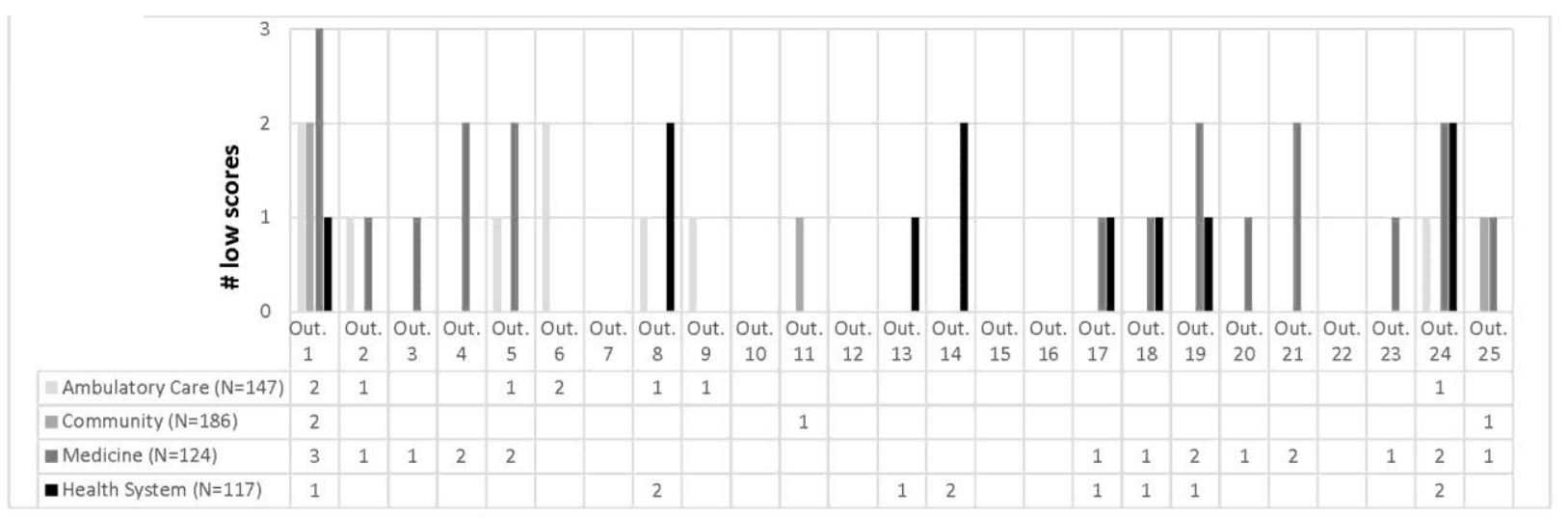

Figure 2: 2019-2020 APPE skills outcome low scores (less than 2: range 1-5)

\section{Discussion}

This study could analyse student achievement of the APPE learning outcomes for the purposes of accreditation, quality improvement, and practice readiness. This study showed that the preceptors of the Medicine rotation rated the learning outcomes low more frequently. This occurred eight times for six of the Professionalism learning outcomes (motivation, commitment to excellence, accountability, time management and organisation, communication, and professional demeanour) and 20 times for 13 of the Skills learning outcomes, covering communication, drug information, pharmacist patient care process (PPCP), and other skills such as patient safety, critical thinking, and interprofessional collaborative practice. While Community rotation preceptors gave a low score rating much less frequently, having occurred zero times for the Professionalism learning outcomes and only four times for the Skills learning outcomes (verbal communication, prescription interpretation, and interprofessional collaborative practice). The reasons for this are unknown, and further study is needed to elucidate these discrepancies.

Skills learning outcome 1 , which is related to verbal communication, was most frequently given a low score. Further investigation and continued monitoring of this learning outcome are needed.

Distilling the data down to the specific rotation site/preceptor may be helpful for future interventions. When three years of data are collected, the results of the analysis would be submitted to the School's Curriculum and Assessment Committees for quality improvement purposes. This one-year review indicates no need for intervention since it appears that the Student Pharmacists are practice-ready at this time. Empirically, it is believed that if the percentage of meets evaluations falls below 95\%, then further investigation is needed by the Office of Experiential Education and Curriculum Committee. The validity of this study may suffer due to subject (preceptor) 
variability in their approach to grading students, leading to intra-rater variability. With over 200 preceptors grading students in 13 different States, there will undoubtedly be variabilities in grading. Frequent preceptor training is a method that may be helpful to minimise this variability but does have participation challenges.

\section{References}

Accreditation Council for Pharmacy Education (ACPE). (2015a). Accreditation standards and key elements for the professional program in pharmacy leading to the doctor of pharmacy degree: Standards 2016. Available at: www.acpeaccredit.org/pdf/Standards2016FINAL.pdf

Accreditation Council for Pharmacy Education (ACPE).

(2015b). Guidance for the accreditation standards and key elements for the professional program in pharmacy leading to the doctor of pharmacy degree: Guidance for Standards 2016. Available at: www.fip.org/files/content/priorityareas/workforce/nanjing-statements.pdf

International Pharmaceutical Federation (FIP). (2017). Nanjing Statements: Statements on Pharmacy and Pharmaceutical Sciences Education. Available at: www.fip.org/files/content/priority-

areas/workforce/nanjing-statements.pdf

Katoue, M. G., \& Schwinghammer, T. L. (2020).

Competency-based education in pharmacy: A review of its development, applications, and challenges. Journal of Evaluation in Clinical Practice, 26(4), 1114-1123.

https://doi.org/10.1111/jep.13362

Law, M., Bader, L., Uzman, N., Williams, A., \& Bates, I. (2019). The FIP Nanjing Statements: Shaping global pharmacy and pharmaceutical sciences education. Res Social Adm Pharm, 15(12), 1472-1475.

https://doi.org/10.1016/j.sapharm.2019.03.013 